\title{
PARTICULARITIES OF THE EDUCATIONAL LEADERSHIP IN THE MILITARY ENVIRONMENT
}

\author{
Benoni SFÂRLOG, Daniel-Sorin CONSTANTIN, Bogdan RACHINĂ \\ "Nicolae Bălcescu" Land Forces Academy, Sibiu, Romania \\ sfarlogb@yahoo.com, cdanielsorin@gmail.com, \\ rachinaflorinbogdan@yahoo.com
}

\begin{abstract}
The military leader is the central pillar of all military structures, whose functionalism is sustained and enhanced by the exercise of an effective leadership. Explaining the role and place of the military leader in an organizational context creates prerequisites for the identification of his/her action situations from an educational perspective. In this context it becomes necessary and useful to investigate the issue of the educational leadership on delimiting the conceptual framework, identifying the exigencies and forms of exercising the educational leadership, as well as the particularities of the educational leadership at the tactical level. From this approach, implications of habit-forming arise.
\end{abstract}

Keywords: Leadership, educational leadership, educational management, leadership training, military leader.

\section{Preliminary considerations}

In the last decades, the theory of educational management and leadership has gained a consistent, complex and interdisciplinary development. However, it is considered that the theoretical foundations do not yet provide a sufficiently explicit conceptual framework for substantiating and generalizing good practice in the field. The theoretical support of effective management and educational leadership practices is a sine qua non condition for the development of the skills of the staff involved in the efficient exercise of the specific leadership roles and concrete educational approaches.

The complex approaches made by deepening the concepts and illustrating explanatory models of management and educational leadership generate the opportunity to study their viability and applicability in different organizational contexts, most often characterized by specific features and particularities. In the military field, at least in the Romanian space, the situation is clear, not only that there are no theoretical and systematic studies on the issue of educational leadership, but neither the doctrinal or the drafting of the training system do not refer directly or implicitly to the methodological concepts and requirements of educational leadership.

Obviously, it is questionable whether and to what extent the models of educational leadership are applicable and useful in the system of training the forces. A careful analysis of the organizational environment from the perspective of the stated criterion points out that, categorically, the military organization and especially the educational environment specific to it is supported both at the level of the training system in its entirety and at the level of each component 
of the training. Therefore, military education, training, exercises and training through application are under the impact of influences exercised in the sphere of educational leadership.

\section{Relevant theoretical considerations}

The assumption that the leadership is the social process of influence that a person exerts on the attainment of other people's goals in a certain organizational context is quasi-unanimously accepted.

The relevant areas of leadership in the educational environment are in the sphere of the educational leadership theory, in the practice of the educational act and in the concrete exercise of the roles and attributions of the educator as a leader of the object structures of education [1]. Regardless of the particularities of the teaching-learning-evaluation process of the leadership role entails an intense process of influencing the behaviours of the training object. The concept promoted by educational leadership theorists has been the foundation of the reform implemented in education in the last decades of the last century. The fundamental thesis of the new paradigm hypothesizes the didactic framework as a leader in didactic and pedagogical activity.

Educational leadership appears as a form of collective leadership, in which the personal and professional skills of the teacher streamline the pedagogical approach through cooperation and collaboration. Thus, the didactic framework is a visionary that inspires and motivates both the students and the teachers, sometimes influencing them decisively for the achievement of the educational goals.

The leadership role of the teacher is distinguished by the complexity of its manifestations, characterized by the following aspects:

- acts and leads according to a set of personal and professional inner values and thus impresses its values in organizational culture; is fully involved in ensuring the quality of education; relates vertically and horizontally, being an active factor for influencing others; is open to innovation and works together to disseminate and implement progress-generating solutions; analyses the macro and micro educational system and process. In order to exercise its leading role, the educational leader is vested with power and authority. Authority is described as a three-way relationship that is established between a bearer, a subject, and a domain. The authority excludes the use of external means of coercion and is incompatible with persuasion, which implies equality and operates through a process of argumentation. The educational leader has epistemic and methodological authority. Power sources give the leader the opportunity to use different methods, techniques and procedures to influence others. Influencing occurs directly and indirectly through attitude, verbal communication, body language, emotional state, personal example, i.e. through its active involvement. The effectiveness of influencing is conditioned by a number of factors of psychosocial, organizational and especially contextual nature.

The leadership concept of training is most often assimilated to learning-centred leadership that targets the leadership's behaviour, the direction and impact of their influence, and less on the actual process of exerting influence [1]. Thus, three strategies are used to influence learning: modeling, as a power of example, the monitoring, as an active participation in the educational act and the timely realization of the feedback and dialogue, as a way to achieve the exchange of collegial ideas as well as with leaders from the educational system.

We start from premises that the officers with powers in the field of the training of the forces meet all the requirements for being unequivocally included in the chair of the educational leaders. Obviously, the subunit commander is the key factor in the exercise of educational leadership. 
Educational leadership theorists have identified a typology of their models, highlighting: managerial, participative, transformational, distributed, transactional, postmodern, emotional, circumstantial, moral and training leadership. [1]. They highlight the procedural complexity of educational leadership, its various nuances, specific in a structural, functional and even conceptual plan.

Managerial leadership is most often unidirectional, it targets the leader's attribute at the top of the hierarchy that sets policies, shapes formal goals, and adopts the innovations it deems necessary. It is based on the rational behaviour of the members of the organization.

Participatory leadership, transformational leadership and distributed leadership complement the individual leadership with a defining aspect for collective leadership, the formal leader being in fact a facilitator of the influence process, collegiality being the foundation of their essence. A variety of aspects are envisaged regarding the vision and objectives of the educational system, the stimulation and support of leaders, the good practices and the values promoted, the personnel involved in the decision making and, more recently, the involvement of the existing expertise in the organization.

Transactional leadership involves the appropriate exchange of resources as support for the relationship between the leader and the followers, eluding the vision and values of the organization.

Postmodernist leadership is insufficiently shaped from a theoretical point of view, but most theorists assume in key positions concepts like language, subjectivity and meaning. Emotional leadership is also a subjective model that highlights the individual's role in the system and process. According to it, emotion as a social construct sometimes causes perception to become reality.

Circumstantial leadership highlights the impact of the ambiguity climate in an educational context with direct reference to the ambiguity of purpose, power, experience and success. The advantages of contextualizing leadership are thus confirmed.

Moral leadership promotes the key role of the leader in shaping a culture of learning in configuring organizational culture by affirming values, beliefs and ethics in an organizational context.

The relevant defining notes of these models were the basis for selecting criteria and indicators describing the specificities and particularities assumed to be analysed in this analytical approach.

\section{Design of the research}

Our study on the issue of Educational leadership in a military organizational context aims at identifying the peculiarities specific to the educational process in the military environment and outlining the guidelines for the training and professional development of those invested with the responsibility of designing and managing the training of the forces.

In order to accomplish the proposed goal we have formulated the following objectives: a) identifying the exigencies and actual forms of exercising the military educational leadership; b) identifying the characteristics of the military educational leadership at tactical level c) explaining the formative implications.

The approach of investigating the assumed issues is viable and plausible by formulating hypotheses: a) in the military educational environment, leadership has specific defining characteristics, the particularizing aspects being induced by intra and extra organizational factors; $b$ ) commanders of military structures as educational leaders exercise in a differentiated way and in a combined manner the exigencies of different types of educational leadership.

In order to verify the hypotheses and achieve the objectives, we adopted the qualitative research method on a sample of 18 officers involved in the design, deployment and assessment of military training. 
In our view, Military Education Leaders are all commanders of military structures as well as staff in the profile structures that manage the design, deployment and evaluation of forces' training. We applied a questionnaire that structured the following aspects: level of knowledge of the concept of educational leadership; the formal structure involved in decision-making in the field; leadership participation in decisionmaking; values promoted by educational leadership in organizing and conducting training of forces; the degree of uncertainty manifested in the military educational context; contextual adaptation of educational leaders to demanding and challenging realities.

\section{Brief interpretation of results}

The interpretation of the results confirms the hypotheses formulated and highlights relevant aspects of the particularities of the educational leadership in the military environment. Thus, the knowledge of the concept and the demands of the educational leadership proved to be at a superior level. The subjects surveyed have fully demonstrated that the differences between educational management and educational leadership master the mechanism of different educational leadership models and, in particular, they are able to nuance and contextualize their applicability in the educational process. Regarding the formal structure, it is emphasized the institutionalized rigor in the field of setting the objectives for the training system in its entirety, as well as for each of its components. It is important to standardize the training of forces through which the goals, objectives and modalities of structuring and evaluating the educational act are clearly established at the institutional level. An institutional framework for discussing the training objectives, the basic concepts of the training process, as well as the optimization modalities with special emphasis on the introduction of innovation is created. It is considered essential that, in a positive sense, the design of the training starts from the mission, from the essential requirements for them. Correlated with educational management, educational leadership comes with specific ways of exerting influence throughout the educational system.

Leaders' participation in decision-making is manifested at a higher level the notion of leader of leaders, being well understood and applied in the military educational context. Everything that is done for the design of the instruction in each training cycle confirms the good cooperation, the harmony at the collegial level as well as in a vertical position. The participatory process involving officers at all levels of the training system is based on common values and rigorously analysed and assumed outcomes.

Values promoted by military educational leadership are based on organizational goals, interests, and objectives, but there is the possibility of certain discrepancies between organizational and individual goals. The degree of their manifestation is insignificant and sporadic, although an unattended management of the subunit and unit realities may lead to major dysfunctional ties.

With regard to the degree of uncertainty manifested in the military educational context it is considered that it is not a relevant characteristic for the military educational system, the ambiguity being present at both macro and microstructural level. The practice of developing individual training programs and training programs for missions eliminates uncertainty or the unknown, lack of perspective or scope at any stage in managing the training process of forces. However, there are possibilities for the occurrence of some dysfunctions generated from the external environment to the structures involved in the training process and consequently it becomes necessary to limit the interferences in the design of the training.

The contextual adaptation of educational leadership is commonly perceived as an 
obvious necessity, as an ingredient of success. The adaptability of military educational leaders, regardless of the hierarchical level in which they exert their influence, attract the efficient use of resources, the avoidance of functional incompatibilities or discontinuities in conceptual or operational terms. Respondents' answers make direct connections to aspects of emotional implications in leadership on the contextual adaptability coordinates, actors involved in leading the training of the military proving personal, social and professional qualities or competencies to operate with discernment and accordingly to the problematic situations or challenges caused by social order addressed to military structures involved in education, instruction or exercises.

A separate distinction, highlighted by $84 \%$ of the respondents, shows training by implementation, in the sense that in this case there is no formal structuring, the educational objectives are implicit and the training is preponderantly individualized. This is why the role of educational leadership is growing. The ways of influencing are adapted and implemented in a wider context of fulfilling the functional attributions. The chance of success is greatly enhanced by the application and capitalization of the advantages offered by the modern methodology of adult education.

\section{Conclusions}

The results of this research highlight the viability and applicability of the educational leadership theory in the military educational context. The training of forces is essentially, through all its components, a teaching-learning-evaluation process and the direct influences exercised formally or informally are obvious. Thus, the military educational leadership meets the prerogatives of a process with major implications for the efficiency of the training of the military personnel and the increase of the operational capacities of the military structures. As we pointed out, some models of educational leadership are less relevant to the military educational environment. The particularities identified outline the possibility of deepening and consolidating the issue in subsequent studies.

\section{References}

[1] Bezede, R., Repere psihopedagogice ale leadershipului educational, Teză de doctorat, Chisinău, 2015

[2] Bush,T., Glover, D., School leadership: Concepts and Evidence, Nottingham, p.10

[3] Tony Bush, Leadership și management educațional: teorii și practici actuale, Editura Editura Polirom, Iaşi, 2015, p. 13.. 